\title{
The Proof of the Pudding: Using Library of Congress Proof Slips
}

\begin{abstract}
This paper points out the many uses to which LC proof slips can be put in medium-sized academic libraries and compares them to accomplishing the same functions in other, more traditional, ways. A sample routine for maximum use of proof slips in a technical services area is described. Economy and efficiency considerations seem to warrant their increased use.
\end{abstract}

\section{L}

IIBRARY OF CONGRESS proofsheets have been available to libraries for a long, long time. Unfortunately, some academic libraries which might find it profitable to use them are not doing so. These libraries might benefit from a review of some of the ways in which proofsheets are being employed by other libraries. On the other hand, some of the libraries now purchasing this valuable resource are not taking full advantage of it. The latter might benefit from considering a system in which proofsheets are used throughout the resource-building and processing activities of a medium-sized university library. After noting some current applications, such a system will be outlined below.

First, a few facts about the proofsheets may be desirable to set the scene. They are created when copy for new Library of Congress catalog cards is run on long sheets, five cards at a time. Complete sets of these sheets, or partial sets based on broad subject classifications, may be purchased from the Card Division. ${ }^{1}$

${ }^{1}$ U.S. Library of Congress, Processing Department, Cataloging Service, Bulletin 73, Washington, D.C.: 1965 , p. 3.

Mr. Waters is Chief, Reference Services Division, National Library of Medicine, and Mr. Costabile is Special Assistant to the Chief, Technical Services Division, National Library of Medicine.
Complete sets, mailed weekly, cost $\$ 140$ per year. Cut to card size and punched (in the form referred to hereafter as proof slips), the charge is $\$ 185$. Daily mailings are available for an additional $\$ 25$. About eighty-five thousand of the individual slips are being produced annually, although a much larger volume may safely be predicted for the future because of the existence of the Title II program. When the Library of Congress computerizes its current cataloging, it might be able to offer an individualized proofslip service, tailored to the measure of a customer library's requirements by subject, language, etc., with self-correcting feedback through a record of the cards ordered by the customer.

Libraries can use these slips for many purposes: to verify book order information; to obtain LC card numbers before ordering cards; to produce their own catalog cards; even to select current materials for purchase.

Many of the libraries which purchase the complete set alphabetize the slips by main entry and cumulate the file through one or more calendar years. This file may be used, as noted above, to verify or to obtain more complete information on orders for current titles, in lieu of or before checking many issues of the printed National Union Catalog. A substantial amount of searching time can be saved 
by doing so. Obviously, however, a considerable volume of searching must take place before savings in searching-time can offset the cost of the slips and the cost of maintaining the file, which may require up to twenty hours of alphabetizing and filing per week. It should be noted also that the file will be more up-to-date than the printed catalog, but on the other hand the printed catalogs include typed NUC entries, plus some cross references, which make them more comprehensive than the file. Two recent articles on verification searching do agree on the wisdom of searching a proofslip file to locate information on current imprints, before searching the printed NUC. ${ }^{2}$

Instead of or in addition to using the cumulated file of proof slips as an aid in ordering current imprints, some libraries use the file as an aid in cataloging. If the file is searched so that LC cards may be ordered by card number, there will be savings on card costs, since the first card in a set costs five cents less when ordered by number than when ordered by author and title. ${ }^{3}$ It would be uneconomical to use this file only to obtain card numbers, however, since the cost of file maintenance and searching would offset the lessened cost of the cards.

Some libraries, after locating proof slips in a cumulated file, use them to produce their own catalog cards, rather than ordering them. A thorough study of the problems, methods, and costs of card reproduction was published in $1965,{ }^{4}$ but it is already out of date; for one thing, the cost of Library of Congress cards has gone up since the book was published, and the cost of Xeroxing cards has gone down. At the present time, it can be stated that any library with a Xerox 914

${ }^{2}$ Gerald J. Lazorick and Thomas L. Minder, "A Least Cost Searching Sequence," CRL, XXV (March 1964), 126-28; and Ashby J. Fristoe, "The Bitter End," Library Resources and Technical Services, X (Winter 1966), 91-95.

3 U.S. Library of Congress, op. cit., p. 1.

4 ALA, Library Technology Project, Catalog Card Reproduction: Report on a Study Conducted by George Fry and Associates, Inc. (Chicago: ALA, LTP, 1965). copier available can produce reasonably good catalog cards for about two cents per card, over and above the cost of the original copy. This price includes all labor, materials, and meter charges, but assumes that the monthly rental and minimum monthly charges are covered by other uses of the machine or by a large volume of card copying. The estimate also posits the use of die-cut stock in strips of eight pre-punched cards, which is now available commercially. (The study mentioned above assumed that only four cards at a time were copied, and that the library required a power cutter to cut plain stock.) Using the figure given above, a set of five Xeroxed cards would cost about ten cents, as against a comparable set of LC cards costing no less than thirty-four cents. The cost of a year's proof slips would be more than covered by savings in Xeroxing a thousand sets of cards. (This analysis bypasses the cost of filing and pulling proof slips, which has been covered in a recent article by Donald Axman. ${ }^{5}$ )

Additional economies can be realized if the LC call number is accepted and is typed on the proof slip before cards are produced. One typing and one proofreading will then replace several. Furthermore, the time and effort involved in keeping records of LC cards on order may be substantially reduced since cards can be copied and returned within a short time after proof slips have left the catalog department. Ease in obtaining good quality cards prepared from typed copy for "original" cataloging constitutes one more fringe benefit which can be squeezed from this system.

Selection logically should have been the first function mentioned in discussing the use of proof slips. It is being treated last because there seems to be more resistance to the use of proof slips in selection than for other purposes, and de-

\footnotetext{
${ }^{5}$ Donald H. Axman, "Antidote for the Dormant," Library Journal, XCI (February 1, 1966), 458.
} 
tailed consideration of the pros and cons appears desirable.

This resistance may be because of the fact that some librarians believe that it is desirable to examine a book and to read one or more reviews before making a purchase decision. In any library, however, there are some books which ought to be purchased immediately, regardless of quality as indicated by personal inspection or reviews. This doctrine may seem shocking to some, but a moment's thought should convince them. The larger a library is, the larger the percentage of its current acquisitions which can be purchased without the need for examination or consultation of reviews. Once a certain critical size is reached, knowledge of authors, subjects, publishers, and/or series which should be included in the collection suffices to determine the great majority of selection decisions on current trade items. If this were not true, Publishers' Weekly and prepublication announcements would not be treated as valuable selection tools by many libraries. The largest libraries of course pass even this stage, ordering whole classes of material at a time, through blanket orders for a publisher's output or for all materials in a given subject from a given area. As Vosper points out, large academic libraries are concerned "with the selecting not of individual books but of books in quantity."6

Granted that many libraries could select from proof slips rather than awaiting reviews, it still remains to show why they should do so.

Traditionally, some academic libraries have circulated certain basic announcement and review media such as PW, LJ, TLS, Saturday Review, publishers' catalogs, and publishers' announcements, to subject specialists. These specialists, whether on the library staff or on the

\footnotetext{
' Letter from Robert Vosper quoted by Gertrude Wulfekoetter in Acquisition Work: Processes Involved in Building Library Collections (Seattle: University of Washington Press, 1961), p. 30.
}

faculty, advise on or approve purchase of current titles noted in these media. Many practical limitations are inherent in this procedure. Use of proof slips as a library's major selection tool for current materials may well prove more efficient.

A major disadvantage of the review media is that they afford much less comprehensive coverage of world publishing output than the proof slips do. PW listed 28,595 new titles and new editions in 1965. To bring this figure close to the eighty-five thousand proof slips received annually, it would be necessary to examine a substantial number of additional specialized and foreign media. Thus in terms of quantity a library using the proof slips would have a much greater base to select from than when using the traditional tools of selection. On the other hand, the greater selectivity of the review media means that fewer titles out of scope need to be considered. It must also be admitted that the major traditional media ought to be skimmed for urgently desired items even though proof slips are used as the main selection tool. This can be done by generalists on the library staff, however, without involving specialists.

Another disadvantage in using the general review media for selection lies in their arrangement. Some, like PW, are arranged alphabetically by main entry. A few, such as LJ, group their listings by subject and then alphabetically. Others, like the New York Times Book Review, follow neither pattern. In two of these three formats, the specialist is forced to wade through a great deal of extraneous material to locate items in his field of interest.

Another drawback lies in the fact that issues of general review media tend on occasion to get waylaid on one specialist's desk, thus delaying selection and order of materials in other fields as well as in the one being considered.

All too often the general review media are reviewing and listing the same books. 
Thus the subject specialist has to consider the same titles more than once and these titles may have to be searched more than once: This duplication of effort may be avoided to a great extent if proof slips are the major selection tool.

In some libraries, recommendations are transcribed from the review media to a special form before being referred to a specialist for approval. Ordinarily, less information will be available on these forms than on the proof slips, with their detailed descriptive cataloging (including series notes), and subject cataloging. Cost is not shown on the proof slips, but in larger libraries the cost of a current trade book is seldom a determining factor in its selection. Costs can often be ignored if unintentional purchase of overly expensive materials is forestalled through use of a blanket price limitation on the order form. Support for this view is lent by Lazorick and Minder, who define "adequate information" for ordering purposes without mentioning cost. $^{7}$ In any case, the Library of Congress is now printing the list price on proof slips for books listed in the BNB. This practice could easily be extended to American and other titles. Clearly LC might well do so if enough libraries expressed their interest.

In comparing the traditional media with proof slips as a selection tool, then, the latter would appear to be more comprehensive in scope, easier to limit to the specialists' interests, and less likely to be shortstopped or to create problems of duplication. It would be hard to deny that the unit record has distinct advantages over the journal issue in academic library selection procedures; ventures such as the Library Journal's "Reviewson-Cards" and the increasing use of $3 \times 5$ cards for prepublication announcements by publishers and jobbers confirm the fact.

\footnotetext{
7 Lazorick and Minder, op. cit., p. 126.
}

The procedures for use of proof slips in the selection process are quite simple. Upon receipt, the proof slips are arranged by subject, following the call number to the first or second letters, or as deep in the classification as required to suit the needs of the library.

Prescreening should be done by generalists on the library staff because of the great number of proof slips received. This may require eight or more hours of staff time each week. Titles not within the scope of the collection either because of subject or language limitations can be eliminated at this point. The residue may then be sent to the selection officer(s), selection committee, or faculty members who have responsibility for selection in each subject.

The slips should be returned to the order department in several groups: items approved, those disapproved, and those where further investigation is needed.

\section{Systems Approach}

LC proof slips can be useful in any one or two of the areas mentioned above. Their full benefit can be realized, however, only if they are used throughout the whole technical services operation. One way in which this can be done is described below. A library purchases the complete set and has the weekly delivery arranged by subject. Librarians winnow the chaff and refer the slips to subject specialists. Slips approved for purchase are returned to the order unit. (No file of proof slips would need to be created and maintained to speed verification searching, since these slips bear sufficient information for ordering.) The slips are alphabetized to speed the searching required to determine whether the library already owns or has ordered a copy or edition of an approved title. After searching, book orders can be typed from the information on the slips. (Orders could also be prepared by 
Xeroxing the slips on different colored sheets of paper to create a multiple order form, as at the University of North Carolina. ${ }^{8}$ ) The call numbers are then typed on the slips, and the slips accumulated in groups requiring the same number of cards in a set. After Xeroxing catalog cards, the approximate headings are typed on added entry cards. When the books are received, fully prepared card sets await them, ready for filing after minimal additional work. The slips can then be used in the preparation of an accessions list. This concludes a processing operation characterized by speed, smoothness, and economy throughout.

It has been said that in the total systems approach, each unit of work "is considered in relation to all others to provide a totally integrated and compatible system." 9 Some aspects of technical services work, such as accounting, are not integrated in the system described above, but many others are, making it difficult to conceive of a more comprehensive system short of full automation.

${ }^{8}$ Richard M. Dougherty and Samuel M. Boone, "An Ordering Procedure Utilizing the Xerox 914 Electrostatic Process," Library Resources and Technical Services, X (Winter 1966), 43-50.

- Patricia Sievers and Paul Fasana, Automated Routines in Technical Services (L. G. Hanscom Field, Mass.: AFCRL Research Library, 1964), p. 2.

\section{Conclusion}

The paragraphs above have described how libraries are using proof slips as aids in bibliographic verification; in the book and card ordering processes; in card production; and in selection. In each functional area the use of proof slips has offered certain advantages over traditional methods. A currently feasible technical services system is also described in which proof slips are used throughout, from selection to preparation of an accessions list. All the benefits of proofslip use in each area are retained, and many more are created as a result of the systems approach. The cost of the slips are spread over three or four different operations, rather than one or two, while the costs of filing into and searching through a cumulated file are bypassed.

Only through such an approach, it would seem, can a medium-sized university library take full advantage of the painstaking and expensive bibliographical work done by the Library of Congress. Furthermore, by following this approach even the smaller university libraries, and special libraries using partial sets of the proof slips, can obtain this benefit without worrying unduly about the expense.

Subscription to CRL will after July 1, 1967, include 11 News issues as well as six bimonthly journal issues. Subscription orders postmarked after June 1 will be accepted only at the new rate $-\$ 10.00$ per year. 